\title{
А.Р. НИКИФОРОВ
}

Никитский ботанический сад - Национальный научный центр НААНУ

АР Крым, г. Ялта, 98648, Украина

nbs1812@ukr.net

\section{ГЛЯРЕОФИТОН И БИОЭКОЛОГИЧЕСКАЯ ПРИРОДА ОБЛИГАТНЫХ ГЛЯРЕОФИТОВ ВЕРХНЕГО ПОЯСА ГОРНОГО КРЫМА НА ПРИМЕРЕ LAMIUM GLABERRIMUM (LAMIACEAE)}

К $љ$ ч е в ы е сл о в а: Горный Крым, осыпь, петрофит, аляреофит, Lamium glaberrimum

\section{Вступление}

Одним из важных элементов горного рельефа являются скалы. Слагающая скалу горная порода подвергается выветриванию, растрескивается, ее обломки скатываются вниз. В результате формируется рельеф, который состоит из двух структурных частей: верхней - денудационной и нижней - аккумулятивной. Аккумулятивную часть склона (осыпь) образуют камни, щебень, песок коллювиальные отложения. Параметры слоя коллювия (глубина, мощность и др.) зависят от активности денудации и условий накопления обломков горной породы. Разнообразные факторы дифференцируют аккумулятивный склон на элементы микрорельефа: конусы, лотки и гряды [8].

Коллювий концентрируется у подножия и накапливается в депрессиях, образуя здесь чехол отложений. От скалы регулярно откалываются обломки, и когда угол откоса толщи коллювия начинает превышать угол крутизны склона, верхний слой обломков теряет равновесие, смещается под силой тяжести или вследствие физических воздействий [8]. Поверхность чехла нагревается днем и резко остывает ночью. Конденсируемая из воздуха влага не испаряется, а просачивается в толщу чехла, где размеры обломков уменьшаются, а температурная амплитуда сглаживается. Здесь же образуется особый субстрат - мелкозем. Он состоит из пылеватых глинистых частиц, которые перемешаны со щебнем, песком, минерализовавшимися остатками растений, прослойками почвы. Таким образом, на осыпях в местах накопления коллювия формируется чехол обломков, который дифференцирован на различные по вертикальному расположению, гранулометрическому составу, подвижности, гидротермическим условиям и плодородным свойствам слои.

Экологическую специфику перекрытых коллювием склонов обозначают понятием «феномен (C) А.Р. НИКИФОРОВ, 2014 осыпей» $[9,18]$, а растительность осыпей определяют как «гляреофитон» [14] или «подвижный петрофитон» [4]. Растения гляреофитона подразделяют на биоморфологические группы, которые со времен Карла Шретера (C. Schroeter) - одного из основателей франко-швейцарской ботанической школы - связывают с последовательными фазами зарастания осыпей (фитоценогенеза) [1, $3-5,10,12,15-18]$.

По Шретеру, осыпь изначально представляет собой «безжизненное пространство», свободное от высших сосудистых растений. Первыми на «движущейся осыпи» поселяются корневищные растения, «ползучие в щебне». Они пронизывают обломки во всевозможных направлениях длинными, тонкими, извивающимися корнями и побегами, которые перемещаются вместе со щебнем. Позже на подвижную осыпь проникают растения другого биоморфологического типа - «стелющиеся по поверхности щебня». Для них характерны надземные, олиственные лежачие побеги. Следующую биоморфологическую группу заселяющих осыпь видов составляют «якорные», или «плотинные», растения, «прорастающие корнями или стеблями сквозь щебень». По Шретеру, осыпь с этого момента теряет подвижность и ее пространство осваивают «дерновинные растения». Дерн способствует накоплению мелкозема, что создает условия для развития требовательных к плодородию видов. В результате осыпь окончательно зарастает и приобретает облик, характерный для луговых сообществ. Эта схема преобразования подвижной осыпи по последовательным этапам в ее зарастании, закреплении, задерновании почти дословно воспроизводится разными исследователями в отношении аналогичных объектов $[1,5,10,12,15,16,18]$.

Тезис о первоначальной «безжизненности» осыпей предполагает то, что гляреофитон полностью формируется пришлыми видами. Тем не менее, помимо биоморфологических групп в составе гляреофитона различают экологические группы

ISSN 0372-4123. Ukr. Bot. J., 2014, 71(1) 
видов: факультативные гляреофиты - растения осыпей, которые произрастают и в других типах каменистых местообитаний, а также облигатные гляреофиты - растения, встречающиеся исключительно на осыпях [14]. Таким образом, группа облигатных гляреофитов, несмотря на очевидность ее существования, остается совершенно биоморфологически неопределенной и поэтому дискуссионной.

Цель нашего исследования: выявить биоэкологическую специфику облигатных гляреофитов осыпей верхнего пояса Горного Крыма на примере признаков растений Lamium glaberrimum (K. Koch) Taliev.

\section{Объект и метод исследования}

Объект исследования - растения L. glaberrimum и некоторых других видов в составе гляреофитона у скалы Шаган-Кая (1436 м над у. м.) на восточном склоне Гурзуфской яйлы (рис. 1) и под вершиной Эклизи-Бурун на восточном склоне Чатыр-Дага (1527 м над у. м.). Обе осыпи крутосклонные (угол наклона $\left.30-40^{\circ}\right)$. Коллювий распространен от подножия скал на относительной высоте 40-50 м и более. Видовой состав сообществ, экологическую приуроченность и биоморфологические признаки растений устанавливали по литературным данным и собственным наблюдениям. Растения и состав популяции L. glaberrimum на осыпи ЧатырДага изучали в 2004-2009, 2013 гг, а на склоне Гурзуфской яйлы - в 2012-2013 гг. Растения L. glaberrimum исследовали также ex situ в климатических условиях Южного берега Крыма. С 2005 по 2012 гг. здесь выращивали в увлажняемом плодородном грунте 10 и более растений указанного вида. Семена высеевали по мере их созревания по 10 штук с июля по ноябрь. Условия прорастания семян фиксировали по данным метеостанции «Никитский сад» (208 м над у. м.).

\section{Результаты исследования}

Считается, что «пионерами» при заселении осыпей высшими растениями выступают виды с типичными корневищами. По А.Д. Джураеву [5], эти корневища ветвятся в щебне, образуя побеги с придаточными корнями. Побеги корневища тонкие, эластичные, легко укореняются и выходят на поверхность в форме розеток листьев и цветков. «Передвижение осыпной массы не вредит им, так как они при засыпании быстро развивают много новых побегов, корней и пассивно следуют за движением субстрата» [5, с. 143]. Подземные органы таких растений «... замедляют движение осыпной массы и создают условия для поселения тех растений, которые не могли до этого произрастать на подобных участках» [5, с. 143].

По А.П. Стешенко [12], подземное корневище разрастается под слоем щебенки на глубине 5-10 см. Длинные столоновидные побеги корневища «... как сеткой пронизывают каменистощебенчатое тело осыпи и таким образом закрепляют ее. На поверхность осыпи... выходят лишь верхушки побегов с пластинками листьев. По всей длине... корневищ обычно закладываются спящие почки, из которых затем разовьются новые корневища с надземными побегами» [12, с. 217].

В Горном Крыму В.Н. Голубев при изучении растений у подножия северо-восточного борта скалы Шаган-Кая (рис. 1) выделил щетинистопырейно - лигустиколистноборщевиково - скальнофиалковую ассоциацию (Elytrigia strigosa + Heracleum ligusticifolium - Viola oreades) [4], а модельный тип приспособительной структуры, «общий для растений, произрастающих в условиях подвижного каменисто-щебенчатого субстрата», выявил у Viola oreades M.Bieb. (фиалки скальной) [4].

По В.Н. Голубеву, структурную основу подземной части фиалки составляет толстый «паренхиматозный стержневой корень» с боковыми ответвлениями. Корень располагается в слое «неподвижного щебня», а от него к поверхности отходят корневищные оси. Корневища покрыты корой, внутри имеют склеренхимные тяжи, что повышает их механические свойства. Оси корневища выходят к поверхности, где развиваются розетки листьев и цветоносы [3]. «Со всей убедительностью выступает приспособительный характер описанной структуры к условиям «текучего», подвижного щебенчато-каменистого субстрата» [3, с. 8]. «Описанные черты биоморфоструктуры растений подвижного петрофитона в той или иной степени выражены у всех видов, укореняющихся в слое гумусированного мелкозема и перекрытых сверху щебнистой осыпью. Только такие приспособительные особенности способствуют выживанию и закреплению растений на вначале безжизненной голой осыпи» $[4$, c. 8$]$.

Парадокс заключается в том, что известные виды с подземным корневищем - гипогеогенным 
ризомом - приурочены к различным по экологическим условиям местообитаниям вне осыпей [11], a $V$. oreades, в частности, вообще не произрастает на осыпях южного макросклона Горного Крыма. Популяции $V$. oreades развиваются на северо-восточных склонах на высоте не ниже 1100 м над у. м. в условиях неплотно задернованных почв со щебнисто-каменистыми включениями или же, по В.Н. Голубеву, «на гумусированном мелкоземе» $[3,4,13]$. Этот типичный по своей экологической природе мезофит-микротерм в основном приурочен к редколесьям Pinus sylvestris L., где формирует группировки с Carex humilis Leyss., Alopecurus vaginatus (Willd.) Pall. ex Kunth, Dactylis glomerata L., а также Alchemilla jailae Juz., Cerastium biebersteinii DC., Cruciata taurica (Pall. ex Willd.) Soó, Ranunculus dissectus M.Bieb. Эта фиалка если и выходит за границы сосновых редколесий, то только в случае сочетания конкретных условий: слабого задернования, стабильной влажности и летней прохлады. Местообитания $V$. oreades при наличии рядом с ними денудационных поверхностей действительно могут покрывать обломки горной породы - в карстовой воронке [3], у подножия скалы [4]. Здесь оси подземного корневища $V$. oreades преодолевают щебень, так же как в других условиях - слой каменисто-щебнистой почвы. Настойчивость, с которой $V$. oreades трактуют как «модельный тип подвижных осыпей» [3, 4, 10], вполне объяснима: биоморфологические признаки растений этого вида полностью соответствуют аналогичным параметрам тех корневищных растений, которые, якобы, первыми поселяются на «безжизненном подвижном щебне» $[1,5,12,15,16$, $18]$.

По В.Н. Голубеву, растительность яйлы составляют два эколого-фитоценотических типа: петрофитный и лугово-степной [2]. «Существенная особенность лугово-степных видов на яйле - их способность к развитию и возобновлению среди сомкнутого в надземной части ценоза при наличии сформированной дернины. Это свойство... у петрофитов отсутствует» [2, с. 7]. Петрофиты же «... приспособились к единичному или групповому произрастанию без затенения со стороны других растений и воздействия мертвых растительных остатков в больших скоплениях и дернины» [2, c. 7]. Лугово-степные растения формируют с петрофитами изреженные ценозы на осыпях и скалах: «Пионерами в освоении первично свободных горных пород являются петрофиты, создающие среду для поселения лугово-степных видов. ... Большая часть группировок, в которых обильны петрофитные виды, представляет собой переходную стадию между петрофитной и луговой степью» [2, с. 8]. Выясняется, что растения с подземным корневищем, которые по своей биоэкологической природе не относятся ни к петрофитам, ни к лугово-степным видам [11], не являются первичными поселенцами на осыпях. Для таких видов экологическая сопряженность с условиями «подвижного каменисто-щебенчатого субстрата» не характерна и проявляется только при особых обстоятельствах. В.Н. Голубев отметил, что осыпь у северо-восточного борта Шаган-Кая «уже стабилизировалась, заросла петрофитными видами», а «подвижный щебень» заполняет центральную часть осыпи, которая здесь почти лишена растительности (рис. 1): «начинает осваиваться некоторыми видами растений» [4]. Выясняется, что В.Н. Голубев изучил признаки некоторых видов в составе смешанного сообщества на перекрытом щебнем склоне у подножия скалы (рис. 1, Б) [4], а центральная часть осыпи (рис. 1, А) с местным гляреофитоном осталась вне этого исследования.

Итак, осыпь представляет собой единую по времени формирования и развитию геоморфологическую структуру (рис. 1). В случае существования последовательных фаз в ее зарастании очередной этап «стабилизации» выявлялся бы по преобладающему биоморфологическому типу растений. В действительности же никаких «этапов» и очередности поселения растений здесь не прослеживается. Части аккумулятивного склона с маломощным слоем коллювия занимают смешанные группировки из петрофитов, лугово-степных и даже лесных видов: корневищных, стержнекорневых, луковичных, клубневых, однопобеговых, рыхло- и плотнокустовых растений. Эти растения распространены в сообществах зонального типа, характерных для данного высотного пояса. Проникновение растений из соседних ценозов на осыпь обусловлено способностью видов к миграции, а также разнообразными приспособлениями к произрастанию на каменисто-щебнистой почве. Имеются также локальные популяции петрофитов, которые изолированы на осыпях и отсутствуют в зональных сообществах. Эти популяции опровергают тезис о «первично безжизненной подвижной осыпи». Очевидно, что в ландшафте осыпи местные и пришлые растения распределялись по мере дифференциации экологических ниш. 

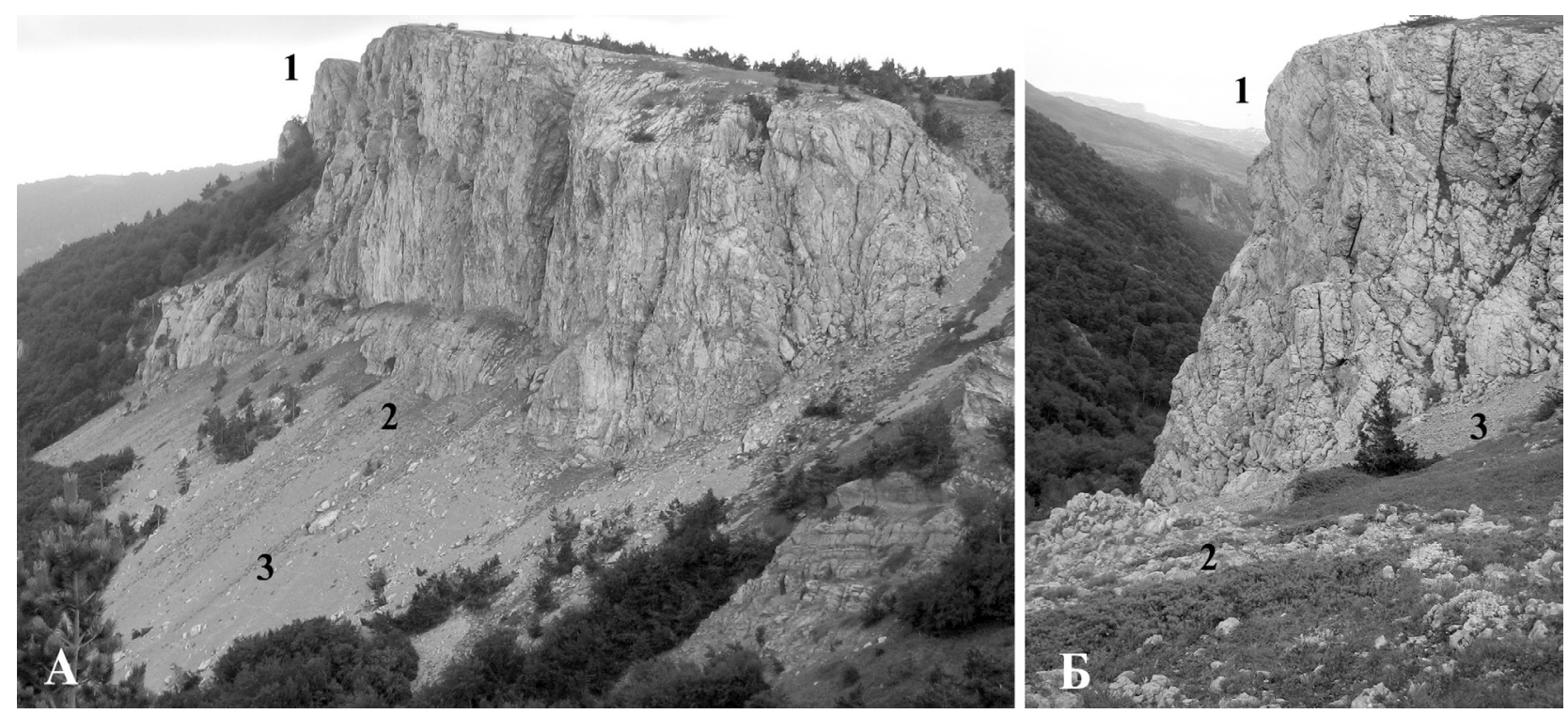

Рис. 1. Осыпь возле скалы Шаган-Кая. А - уклон возле северо-восточного борта Шаган-Кая; Б - общий вид осыпи. У с л о в н ы е о б о з н а ч е н и я: 1 - денудационный склон; 2 - стабильная часть осыпи с маломощным слоем щебня и сообществами петрофитов; 3 - подвижная часть осыпи с чехлом щебня

Fig. 1. Talus near Shagan-Kaya rock. A - slope near the easten side of Shagan-Kaya rock. Б - general view of the talus. $\mathrm{S}$ y $\mathrm{m} \mathrm{b}$ o $1 \mathrm{~s}$ i n d i c a t e: 1 - denudation slope; 2 - stable part of talus with a thin layer of detritus and groups of petrophytes; 3 - crumble part of talus with a layer of detritus

Среди этих ниш наиболее экологически специфичны многослойные чехлы коллювия. Отсутствие здесь ценозов не означает того, что растительность только формируется. На чехле обломков произрастают некоторые петрофиты. Это укорененные в мелкоземе с зоной возобновления на уровне поверхности щебня: Heracleum stevenii Manden., Heracleum ligusticifolium M.Bieb., Rumex scutatus L., Scrophularia goldeana Juz. Здесь же локализованы популяции L. glaberrimum и других облигатных гляреофитов.

Популяции L. glaberrimum обнаружены на крупных по размерам осыпях Ялтинского и Гурзуфского амфитеатров и Чатыр-Дага на высоте 1300-1400 м над у. м., а также на этой же высоте на северном склоне Бабуган-яйлы. Особи вида - травянистые растения со стержнекорневой системой [13]. Популяции малочисленны. На осыпи Чатыр-Дага растения L. glaberrimum (до 500 экземпляров) произрастают компактно в границах локального, расширяющегося к подножию, осыпного конуса и единично в пределах соседнего конуса. Популяция на осыпи Шаган-Кая (более 1000 особей) прослеживается вдоль коллювиального шлейфа (рис. 1, А).
Структурной единицей в системе побегов является моноциклический одноосный монокарпический побег. Этот побег включает зоны возобновления, торможения, обогащения и верхушечного соцветия [6]. Растения размножаются семенами. Способ диссеминации - барохория (осыпание диаспор по длине зоны соцветия - до 10 см). Семена L. glaberrimum прорастают в погребенном мелкоземе под влиянием контрастной амплитуды суточной температуры воздуха и в условиях стабильно высокой влажности. Если эти факторы отсутствуют сразу после диссеминации, то семена проходят фазу биологического покоя, из которого выходят в указанных выше условиях после яровизации. У проростка развиваются утолщенный главный корень и тонкие боковые корни. Синхронно с формированием стержнекорневой системы (глубиной до 5 см) растение посредством гипокотиля внедряется в толщу щебня - до глубины 10 см. На поверхность чехла семядоли и первые листья выносят удлиненные до 2 см черешки или же до поверхности доходят супротивные листья очередных междоузлий с черешками длиной до 3 см.

Растения цветут с первого года жизни, а зимуют в состоянии биологического покоя. Оптимальная среднесуточная температура воздуха для развития 
L. glaberrimum составляет $+15^{\circ} \mathrm{C}$ и выше. Генеративные органы формируются после образования вегетативной сферы побега и только в теплый период. К концу сезона корни втягивают гипокотиль и зону возобновления растения (рис. 2, Б) в мелкозем, а боковые корни расползаются в слое увлажненного субстрата. Это оптимально увеличивает их всасывающую поверхность. Удлиненные части одноосных побегов после плодоношения отмирают, а утолщенные укороченные нижние части одноосных побегов с заложенными почками (в зоне возобновления) зимуют под слоем щебня. Зимующие органы растений ориентированы преимущественно в горизонтальной плоскости (рис. 2, Б). Весной, при повышении температуры воздуха, почки возобновления раскрываются и дают очередную генерацию одноосных побегов. Зона торможения и зона обогащения одноосного побега достигают длины до 15 см каждая. Зона торможения пронизывает погребенный относительно прохладный и влажный слой щебня, а зона обогащения с паракладиями располагается в приповерхностном слое сухого и более теплого щебня. Над щебнем возвышается верхушечное соцветие. Для боковых осей синфлоресценции характерно все большее удлинение в базипетальном порядке, что способствует выведению на поверхность парциальных соцветий [7]. У L. glaberrimum образуется до трех генераций одноосных побегов. Продолжительность жизненного цикла достигает трех лет [7].

Выясняется, что признаки и приспособления, которые традиционно приписывают растениям «подвижных осыпей» [1, 3-5, 10, 12, 15], у облигатного гляреофита $L$. glaberrimum отсутствуют. Растения L. glaberrimum имеют комплекс иных биологических признаков, который полностью соответствует внешним условиям их развития. Исходя из выявленных биологических особенностей L. glaberrimum, проявляются ключевые признаки облигатных гляреофитов: семенное возобновление, распространение семян на короткое расстояние, мезофильность, относительная термофильность и гелиофилия, наличие органов, способных в теплый сезонный период быстро преодолевать слой щебня и выводить вегетативно-генеративную сферу побега к уровню его поверхности, а соцветие - выше этого уровня, зимовка органов возобновления в толще щебня, мелкокорневая стержнекорневая система, краткий жизненный цикл. Растения L. glaberrimum и другие облигатные гляреофиты не удерживают щебень и вообще никак не изменяют среду своего существования. Гипотетическое «зарастание» осыпей привело бы к вымиранию облигатных гляреофитов.

По мере изучения осыпей различных регионов $[1,5,12,14-16,18]$ и, в частности, крымских
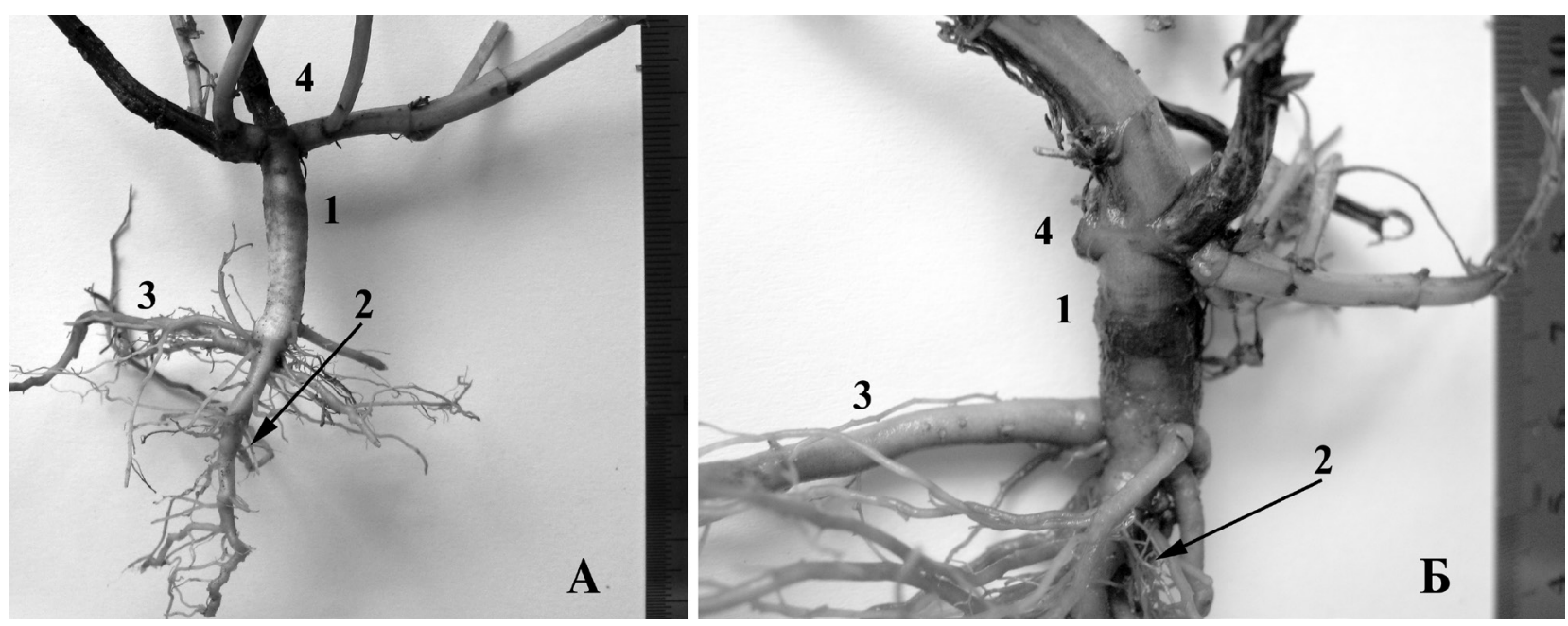

Рис. 2. Корневая система L. glaberrimum. А - корневая система растения первого года жизни; Б - корневая система растений второго года жизни. У с л о в н ы е о б о з н а ч е н и я: 1 - гипокотиль; 2 - главный корень; 3 - боковой корень; $4-$ зона восстановления

Fig. 2. Root system of L. glaberrimum. A - root system of a one-year - old plant. Б - root system of a two- year - old plant. $\mathrm{S}$ y m b o ls in d i c a t e: 1 - hypocotile; 2 - main root; 3 - lateral root; 4 - renewal zone 
осыпей верхнего пояса Главной гряды [3, 4, 9, 10] обозначилась тенденция к сближению (вплоть до полного объединения) облигатных гляреофитов с петрофитами. Так, облигатным гляреофитам Горного Крыма, без каких-либо оснований, приписывают отсутствующие у них признаки. У растений L. glaberrimum, например, выявили «столоновидные побеги» [10], которые почему-то трактуют как органы вегетативного расселения. Интересно, что в предлагаемой классификации видов крымских осыпей по их биологическим признакам [10] L. glaberrimum парадоксально соединили c $V$. oreades. Эти различные по биоморфологии и биоэкологической природе растения очутились в одной группе - вегетативно-подвижных видов осыпей [10]. Кроме этого, L. glaberrimum в статусе диагностического вида включили в новоописанную ассоциацию растительности осыпей верхнего пояса яйлы: Sobolewskio sibiricae - Heracleetum и новую субассоциацию Sobolewskio sibiricae Heracleëtum lamietosum glaberrimi [9]. Петрофиты, упомянутые как диагностические виды данных синтаксонов, быть может, действительно имеют друг с другом устойчивые фитоценотические связи, но L. glaberrimum к таким группировкам не относится.

Облигатные гляреофиты и петрофиты - это виды различного происхождения и разной биоэкологической природы. Очевидно, что облигатные гляреофиты являются извечными обитателями многослойных чехлов - единственной благоприятной среды для их развития на осыпях. Представления о чехле обломков как о «прибежище» для «видов-неудачников», которые когда-то не выдержали конкуренцию с петрофитами в какихто иных, «более выгодных» местообитаниях [9, $10,18]$, - ошибочны. Это косвенно подтверждает автор приведенной выше синтаксономической классификации: «Прияйлинские осыпи являются очень специфическими местообитаниями с экстремальными для растений условиями существования, поэтому многие виды, входящие в состав синтаксона, являются облигатными гляреофитами» [9, с. 10]. Иными словами: специфические экологические условия местообитаний облигатных гляреофитов экстремальны для петрофитов, облигатные гляреофиты представляют собой особый биоэкологический тип растительности.

\section{Выводы}

Растительность аккумулятивного склона формируется синхронно с появлением осыпного ландшафта и по мере дифференциации экологических ниш. Этапы в стабилизации осыпи и фазы ее зарастания отсутствуют.

Приспособительный комплекс признаков облигатных гляреофитов осыпей верхнего пояса Главной гряды Крымских гор типа L. glaberrimuт включает семенное возобновление, распространение семян на короткое расстояние, термофильность, мезофильность, гелиофилию, наличие органов, быстро удлиняющихся в благоприятный сезонный период и выводящих вегетативно-генеративную сферу побегов к поверхности слоя щебня, мелкокорневую систему, зимовку органов возобновления под толщей щебня, краткий жизненный цикл.

Облигатные гляреофиты не входят в состав синтаксонов типичной петрофитной растительности.

\section{СПИСОК ЛИТЕРАТУРЫ}

1. Альпер В.Н. Краткий очерк флоры и растительности известнякового массива Фишта и Оштена // Тр. Кавказ. гос. заповедника. - Майкоп, 1960. - Вып. 6. - С. 3-56.

2. Голубев В.Н. Первичное зарастание и восстановительная сукцессия растительности на Никитской яйле в условиях заповедности // Тр. Никит. ботан. сада. 1982. - 86. - С. 7-25.

3. Голубев В.Н. К биоэкологии фиалки скальной в Крыму // Бюл. Никит. ботан. сада. - 1989. - Вып. 68. - С. 5-9.

4. Голубев В.Н. Подвижный петрофитон в высокогорьях Крыма // Бюл. Никит. ботан. сада. - 1992. - Вып. 74. C. 5-9.

5. Джураев А.Д. Растительность первичных осыпей высокогорий Гиссарского хребта и ее роль в их закреплении // Пробл. ботаники. - Растительный мир высокогорий и его освоение. - 1974. - № 12. C. $142-144$.

6. Никифоров А.P. Особенности жизненного цикла и морфоструктура растений реликтового эндемика Горного Крыма Lamium glabbirimum (Lamiaceae) // Укр. ботан. журн. - 2009. - 66, № 5. - С. 666-672.

7. Никифоров А.Р. Синфлоресценция и побегообразование Lamium glabbirimum (Lamiaceae) - реликтового эндемика флоры Горного Крыма // Ботан. журн. 2012. - 97, № 8. - С. 95-99.

8. Леонтьев О.К., Рычагов Г.И. Общая геоморфология. М.: Высш. шк., 1988. - 319 с.

9. РыфффЛ.Э. Sobolewskio sibiricae-Heracleetum(Thlaspietea rotundifolii) - новая ассоциация растительности прияйлинских осыпей Горного Крыма // Бюл. Никит. ботан. сада. - 2007. - Вып. 94. - С. 9-13.

10. РыффЛ.Э. Биологические группы растений каменистых осыпей Горного Крыма // Экосистемы Крыма, их оптимизация и охрана: темат. сборн. науч. трудов. Симферополь. - 2005. - Вып. 15. - С. 64-70. 
11. Серебряков И.Г., Серебрякова Т.И. О двух типах формирующихся корневищ у травянистых многолетников // Бюл. Моск. об-ва испыт. природы. Отд. биол. - 1965. - 70, № 2. - С. $67-81$.

12. Стешенко А.П. О сезонном ритме развития и морфологии растений каменистых осыпей высокогорий Памира // Пробл. ботаники. Растительный мир высокогорий и его освоение. - 1974. - № 12. - С. 213-219.

13. Червона книга України. Рослинний світ / За ред. Я.П. Дідуха. - К.: Глобалконсалтинг, 2009. - 912 с.

14. Шхагапсоев C.X. Географический анализ скальноосыпной флоры Кабардино-Балкарского высокогорного государственного заповедника // Горные регионы: природа и проблема рац. использования ресурсов. - 1987.- С. 51-56.

15. Шхагапсоев C.X. Растительность и процессы зарастания осыпей альпийского пояса в Кабардино-Балкарии // Изв. Сев.-Кавказ. науч. центра высш. шк. Естеств. науки. - 1988. - № 2. - С. 5-9.

16. Kosiński $M$. Roslinnośc piargów wysokogórskich: ekologia i zróżnicowanie // Wiad. Bot. - 1994. - 38(3-4). - S. 45-52.

17. Schroeter C. Das Pflanzenleben der Alpen. - Zurich, 1926. - $1288 \mathrm{~S}$.

18. Valachovič $M$. Historický vývoj názorov na vyššic syntaxóny radu Thlaspietalia rotundifolii $\mathrm{v}$ Európe a na Slovensku // Preslia. - 1990. - 62(2). - S. 131-137.

Рекомендует в печать

Я.П. Дидух

Поступила 30. 05. 2013 г.

\section{О.Р. Никифоров}

Нікітський ботанічний сад - Національний науковий центр НААНУ (НБС - ННЦ), м. Ялта

\section{ГЛЯРЕОФІТОН І БІОЕКОЛОГІЧНА ПРИРОДА ОБЛІГАТНИХ ГЛЯРЕОФІТІВ ВЕРХНЬОГО ПОЯСУ ГІРСЬКОГО КРИМУ НА ПРИКЛАДІ LAMIUM GLABERRIMUM (LAMIACEAE)}

Біоморфологічні ознаки рослин, які інтерпретували як адаптивні до умов рухливих осипів: розгалужені кореневища, потужні та глибокі стрижнекореневі системи, що пронизують осип, тощо, характеризують цілком інші екологічні умови. Рослинність осипного схилу формується не етапами в міру заростання осипу та його стабілізації, а синхронно з появою цього ландшафту. На прикладі рослин Lamium glaberrimum (K. Koch) Taliev виділені ключові ознаки облігатних гляреофітів: насіннєве відновлення, розповсюдження насіння на коротку відстань, відносна термофільність, мезофільність, геофілія, здатність гіпокотилю та пагонів видовжуватися у сприятливий сезонний період та швидко долати шар щебеню, дрібнокоренева система, зимівля органів відновлення в товщі щебеню, нетривалий життєвий цикл. Особливості біоекологічної природи не уможливлюють занесення облігатних гляреофітів до складу синтаксонів петрофітної рослинності.

Ключов і слов а: Гірський Крим, осип, петрофіт, гляреофiт, Lamium glaberrimum.

\section{O.R. Nikiforov}

Nikita Botanical Gardens - National Scientific Centre NAASU (NBG-NSC), Yalta

\section{GLAREOPHYTON AND BIOECOLOGICAL FEATURES OF OBLIGATE GLAREOPHYTES IN THE UPPER ZONE OF THE MOUNTAIN CRIMEA: A CASE STUDY OF LAMIUM GLABERRIMUM (LAMIACEAE)}

Biomorphological characteristics of plants, previously interpreted as features adaptive to the conditions of crumble talus (such as spreaded rhizomes, powerful and deep main root system penetrating talus, etc.), in fact indicate quite different ecological conditions. Vegetation of a crumble slope is formed not stepwise in parallel with overgrowing talus and its stabilization, but simultaneously with the formation of this landscape. Using Lamium glaberrimum (K. Koch) Taliev as a case study, the key characteristics of obligate glareophytes have been determined: seed reproduction, short-distance dispersal of seeds, thermophily, mezophily, heliophily, ability of the hypocotile and shoots to lengthen in favourable periods and to overcome quickly the layer of detritus, shallow root system, overwintering of renewal organs in the detritus and a short life cycle. Biological peculiarities do not allow to include obligate glareophytes into syntaxa of petrophytic vegetation.

Ke y words: Mountain Crimea, talus, petrophyte, glareophyte, Lamium glaberrimum. 